\title{
New density measurements on carbonate liquids and the partial molar volume of the $\mathrm{CaCO}_{3}$ component
}

Received: 12 March 2003/ Accepted: 18 June 2003/Published online: 2 September 2003

(C) Springer-Verlag 2003

\begin{abstract}
Density measurements on nine liquids in the $\mathrm{CaCO}_{3}-\mathrm{Li}_{2} \mathrm{CO}_{3}-\mathrm{Na}_{2} \mathrm{CO}_{3}-\mathrm{K}_{2} \mathrm{CO}_{3}$ quaternary system were performed at 1 bar between 555 and $969^{\circ} \mathrm{C}$ using the double-bob Archimedean method. Our density data on the end-member alkali carbonate liquids are in excellent agreement with the NIST standards compiled by Janz (1992). The results were fitted to a volume equation that is linear in composition and temperature; this model recovers the measured volumes within experimental error $( \pm 0.18 \%$ on average, with a maximum residual of $\pm 0.50 \%$ ). Our results indicate that the density of the $\mathrm{CaCO}_{3}$ component in natrocarbonate liquids is $2.502( \pm 0.014) \mathrm{g} / \mathrm{cm}^{3}$ at $800{ }^{\circ} \mathrm{C}$ and $1 \mathrm{bar}$, which is within the range of silicate melts; its coefficient of thermal expansion is $1.8( \pm 0.5) \times 10^{-4} \mathrm{~K}^{-1}$ at $800{ }^{\circ} \mathrm{C}$. Although the volumes of carbonate liquids mix linearly with respect to carbonate components, they do not mix linearly with silicate liquids. Our data are used with those in the literature to estimate the value of $\bar{V}_{\mathrm{CO}_{2}}$ in alkaline silicate magmas $\left(\geq 20 \mathrm{~cm}^{3} / \mathrm{mol}\right.$ at $1400{ }^{\circ} \mathrm{C}$ and $20 \mathrm{kbar}$ ), where $\mathrm{CO}_{2}$ is dissolved as carbonate in close association with $\mathrm{Ca}$. Our volume measurements are combined with sound speed data in the literature to derive the compressibility of the end-member liquids $\mathrm{Li}_{2} \mathrm{CO}_{3}, \mathrm{Na}_{2} \mathrm{CO}_{3}$, and $\mathrm{K}_{2} \mathrm{CO}_{3}$. These results are combined with calorimetric data to calculate the fusion curves for $\mathrm{Li}_{2} \mathrm{CO}_{3}, \mathrm{Na}_{2} \mathrm{CO}_{3}$, and $\mathrm{K}_{2} \mathrm{CO}_{3}$ to $5 \mathrm{kbar}$; the calculations are in excellent agreement with experimental determinations of the respective melting reactions.
\end{abstract}

Editorial responsibility: I Carmichael

Q. Liu $(\bowtie) \cdot R$. A. Lange

Department of Geological Sciences,

University of Michigan, 2534 C.C. Little Building,

Ann Arbor, MI 48109-1063, USA

E-mail: qiongl@umich.edu

Fax: + 1-734-7634690

\section{Introduction}

The thermodynamic and transport properties of carbonatite melts are of considerable interest to geologists, despite the fact that they are volumetrically sparse compared to other igneous rocks. They are efficient agents of mantle metasomatism because of their high mobility and high concentration of incompatible trace elements. They are also an economically important repository for $\mathrm{Nb}$, rare earth elements, fluorite, and phosphate. Carbonatite melts are frequently associated with alkaline magmas such as nephelinites, melilitites and phonolites, and may play a role in their genesis. Nonetheless, the physical properties of these novel igneous liquids are poorly known, especially for those rich in the $\mathrm{CaCO}_{3}$ component (Treiman and Schedl 1983; Wolff 1994).

Both mantle-derived and highly evolved natrocarbonatite melts contain substantial concentrations of the $\mathrm{CaCO}_{3}$ component (up to $36 \mathrm{~mol} \%$ in natrocarbonatites; Church and Jones 1995). Yet, most of the density data in the literature are for alkali carbonate liquids (Janz 1992), owing to their role as electrolyte materials for fuel cells. The density of pure $\mathrm{CaCO}_{3}$ liquid cannot be directly measured because it decomposes into calcium oxide and carbon dioxide at temperatures below the melting point at 1 bar. However, density measurements can be made on alkali carbonate melts containing substantial concentrations of $\mathrm{CaCO}_{3}(\leq 50 \mathrm{~mol} \%)$ under a stream of $\mathrm{CO}_{2}$ at 1 bar (Dobson et al. 1996). We have applied this technique in order to derive the partial molar volume and thermal expansivity of the $\mathrm{CaCO}_{3}$ component in alkali carbonate melts. In order to construct a model equation to calculate carbonate melt densities in the $\mathrm{CaCO}_{3}-\mathrm{Li}_{2} \mathrm{CO}_{3}-\mathrm{Na}_{2} \mathrm{CO}_{3}-\mathrm{K}_{2} \mathrm{CO}_{3}$ system, it is necessary to test whether the volumes of these liquids vary linearly with composition or not. Thus the density of several, mixed alkali carbonate melts were also measured. 


\section{Experimental methods}

Seven alkali carbonate liquids were chosen for this study, including the pure end-member liquids $\mathrm{Li}_{2} \mathrm{CO}_{3}, \mathrm{Na}_{2} \mathrm{CO}_{3}$, and $\mathrm{K}_{2} \mathrm{CO}_{3}$, three binary carbonates $(\mathrm{Na}-\mathrm{K}, \mathrm{Na}-\mathrm{Li}, \mathrm{K}-\mathrm{Li})$ and one ternary carbonate $(\mathrm{Li}-\mathrm{Na}-\mathrm{K})$. In addition, two $\mathrm{CaCO}_{3}$-bearing (50 and $15 \mathrm{~mol} \%$ ) compositions were also chosen. All samples (compositions are given in Table 1) were synthesized by mixing appropriate proportions of reagent grade $\mathrm{K}_{2} \mathrm{CO}_{3}, \mathrm{Na}_{2} \mathrm{CO}_{3}, \mathrm{Li}_{2} \mathrm{CO}_{3}$ and $\mathrm{CaCO}_{3}$. The loss on ignition of all reagent powders was determined prior to weighing the reagents for sample synthesis. To ensure sample homogeneity, the powders were weighed out and put directly into the glass holder of an electric blender; the powders were then mixed at high-speed for several minutes. The mixed powders were then

Table 1 Composition of carbonatite liquids (mole fraction)

\begin{tabular}{|c|c|c|c|c|c|}
\hline Sample & $\mathrm{Li}_{2} \mathrm{CO}_{3}$ & $\mathrm{Na}_{2} \mathrm{CO}_{3}$ & $\mathrm{~K}_{2} \mathrm{CO}_{3}$ & $\mathrm{CaCO}_{3}$ & $\mathrm{~g}$ fresh wt. \\
\hline $\mathrm{Li}_{2} \mathrm{CO}_{3}$ & 1.000 & & & & 73.891 \\
\hline $\mathrm{Na}_{2} \mathrm{CO}_{3}$ & & 1.000 & & & 105.989 \\
\hline $\mathrm{K}_{2} \mathrm{CO}_{3}$ & & & 1.000 & & 138.206 \\
\hline$(\mathrm{LiNa})_{2} \mathrm{CO}_{3}$ & 0.520 & 0.480 & & & 89.298 \\
\hline $\mathrm{LiKCO}_{3}$ & 0.500 & & 0.500 & & 106.049 \\
\hline$(\mathrm{NaK})_{2} \mathrm{CO}_{3}$ & & 0.590 & 0.410 & & 119.198 \\
\hline$(\mathrm{LiNaK})_{2} \mathrm{CO}_{3}$ & 0.435 & 0.315 & 0.250 & & 100.081 \\
\hline $\mathrm{KCa}_{0.5} \mathrm{CO}_{3}$ & & & 0.500 & 0.500 & 119.147 \\
\hline$\left(\mathrm{LiNaKCa}_{0.5}\right)_{2} \mathrm{CO}_{3}$ & 0.370 & 0.268 & 0.213 & 0.150 & 100.082 \\
\hline
\end{tabular}

${ }^{a}$ g.f.w. $=\sum X_{i}(M W)_{i}$, where $X_{i}$ is the mole fraction of each carbonate component, $(\mathrm{MW})_{\mathrm{i}}$ is the molecular weight of each carbonate component fused directly in the density $\mathrm{Pt}$ crucible at $50{ }^{\circ} \mathrm{C}$ above their respective liquidus temperatures. The samples containing $\mathrm{CaCO}_{3}$ were fused under a stream of $\mathrm{CO}_{2}$.

High temperature density measurements were made on the carbonate liquids using the Pt double-bob Archimedean method described in detail by Lange and Carmichael (1987) and references therein. For each experiment, $\sim 75 \mathrm{~g}$ of the sample powder was loaded step-wise into a Pt crucible ( $7.5 \mathrm{~cm}$ long $\times 3.5 \mathrm{~cm}$ O.D.). The Pt crucible was then placed in a Deltech vertical tube furnace. An electronic balance with a precision of $\pm 0.0001 \mathrm{~g}$ was mounted on an aluminum platform above the furnace to measure the weights of the platinum bobs before and after immersion into the respective liquid. By using two platinum bobs of different mass (26.6 and $11.6 \mathrm{~g})$, but with identical stem diameters $(1 \mathrm{~mm})$, the effect of surface tension on the stem was eliminated. The density of the liquid is calculated from the following equation:

$\rho(T)=\frac{B_{L}(T)-B_{S}(T)}{V_{L}(T)-V_{S}(T)}$

where $B_{L}(T)$ and $B_{S}(T)$ are the buoyancy of the large and small bob, respectively, and $V_{L}(T)$ and $V_{S}(T)$ are the immersed volume of the large and small bob, respectively. The buoyancy is defined as the mass of the bob in air (corrected to vacuum) minus the mass of the bob during immersion in the silicate melt. Two to seven bobs were used to measure the density of each liquid at each temperature to assess the precision and reproducibility of our measurements. Two bobs (one large and one small) allow a single density determination, whereas seven bobs (two different large bobs in duplicate, and three different small bobs) allow twelve density measurements to be made at each temperature. The standard deviations of our density measurements range from $0.05 \%$ for pure $\mathrm{Na}_{2} \mathrm{CO}_{3}$ liquid to $0.58 \%$ for $\mathrm{KCa}_{0.5} \mathrm{CO}_{3}$ liquid, with a mean value of $0.27 \%$ for the entire data set (Table 2, see also Table 8 ).

Table 2 Density and volume of experimental liquids

\begin{tabular}{|c|c|c|c|c|c|c|c|c|}
\hline Sample & $\begin{array}{l}\mathrm{T} \\
(\mathrm{K})\end{array}$ & $\begin{array}{l}\rho \\
\left(\mathrm{g} / \mathrm{cm}^{3}\right)\end{array}$ & $\begin{array}{l}\mathrm{SD} \\
(\%)\end{array}$ & $N^{\mathrm{a}}$ & $\begin{array}{l}\gamma \\
(\mathrm{N} / \mathrm{m})\end{array}$ & $\begin{array}{l}\mathrm{V}_{\text {meas }} \\
\left(\mathrm{cm}^{3} / \mathrm{g} \text { fresh wt. }\right)\end{array}$ & $\begin{array}{l}\mathrm{V}_{\mathrm{calc}} \\
\left(\mathrm{cm}^{3} / \mathrm{g} \text { fresh wt. }\right)\end{array}$ & $\begin{array}{l}\text { Residuals } \\
(\%)\end{array}$ \\
\hline $\mathrm{Li}_{2} \mathrm{CO}_{3}$ & 1039 & $1.817 \pm 0.003$ & 0.17 & 4 & $0.221 \pm 0.005$ & 40.67 & 40.68 & -0.04 \\
\hline $\mathrm{Li}_{2} \mathrm{CO}_{3}$ & 1088 & $1.797 \pm 0.001$ & 0.06 & 4 & $0.253 \pm 0.004$ & 41.12 & 41.09 & 0.07 \\
\hline $\mathrm{Li}_{2} \mathrm{CO}_{3}$ & 1140 & 1.782 & & 1 & 0.264 & 41.47 & 41.52 & -0.14 \\
\hline $\mathrm{Na}_{2} \mathrm{CO}_{3}$ & 1140 & $1.970 \pm 0.001$ & 0.05 & 2 & $0.191 \pm 0.000$ & 53.82 & 53.72 & 0.17 \\
\hline $\mathrm{Na}_{2} \mathrm{CO}_{3}$ & 1190 & $1.948 \pm 0.001$ & 0.05 & 2 & $0.192 \pm 0.001$ & 54.41 & 54.37 & 0.07 \\
\hline $\mathrm{Na}_{2} \mathrm{CO}_{3}$ & 1242 & $1.924 \pm 0.001$ & 0.05 & 2 & $0.183 \pm 0.000$ & 55.10 & 55.05 & 0.09 \\
\hline $\mathrm{K}_{2} \mathrm{CO}_{3}$ & 1190 & $1.897 \pm 0.004$ & 0.21 & 2 & $0.120 \pm 0.013$ & 72.87 & 72.98 & -0.14 \\
\hline $\mathrm{K}_{2} \mathrm{CO}_{3}$ & 1242 & $1.873 \pm 0.003$ & 0.16 & 2 & $0.110 \pm 0.011$ & 73.79 & 73.83 & -0.05 \\
\hline$(\mathrm{LiNa})_{2} \mathrm{CO}_{3}$ & 828 & $2.026 \pm 0.007$ & 0.35 & 9 & $0.245 \pm 0.020$ & 44.08 & 44.08 & -0.01 \\
\hline$(\mathrm{LiNa})_{2} \mathrm{CO}_{3}$ & 935 & $1.980 \pm 0.007$ & 0.35 & 9 & $0.249 \pm 0.016$ & 45.10 & 45.21 & -0.24 \\
\hline$(\mathrm{LiNa})_{2} \mathrm{CO}_{3}$ & 1036 & $1.935 \pm 0.009$ & 0.47 & 9 & $0.236 \pm 0.021$ & 46.15 & 46.28 & -0.28 \\
\hline$(\mathrm{LiNa})_{2} \mathrm{CO}_{3}$ & 1136 & $1.893 \pm 0.009$ & 0.48 & 9 & $0.221 \pm 0.025$ & 47.17 & 47.34 & -0.35 \\
\hline $\mathrm{LiKCO}_{3}$ & 882 & $1.983 \pm 0.010$ & 0.50 & 8 & $0.189 \pm 0.016$ & 53.48 & 53.65 & -0.33 \\
\hline $\mathrm{LiKCO}_{3}$ & 986 & $1.930 \pm 0.008$ & 0.41 & 8 & $0.187 \pm 0.013$ & 54.95 & 54.94 & 0.02 \\
\hline $\mathrm{LiKCO}_{3}$ & 1087 & $1.882 \pm 0.007$ & 0.37 & 8 & $0.170 \pm 0.012$ & 56.35 & 56.18 & 0.29 \\
\hline $\mathrm{LiKCO}_{3}$ & 1158 & $1.850 \pm 0.006$ & 0.32 & 8 & $0.154 \pm 0.010$ & 57.32 & 57.06 & 0.46 \\
\hline$(\mathrm{NaK})_{2} \mathrm{CO}_{3}$ & 1039 & $1.994 \pm 0.003$ & 0.15 & 4 & $0.190 \pm 0.005$ & 59.78 & 59.82 & -0.08 \\
\hline$(\mathrm{NaK})_{2} \mathrm{CO}_{3}$ & 1140 & $1.947 \pm 0.002$ & 0.10 & 4 & $0.177 \pm 0.005$ & 61.22 & 61.28 & -0.10 \\
\hline$(\mathrm{NaK})_{2} \mathrm{CO}_{3}$ & 1242 & $1.900 \pm 0.003$ & 0.16 & 4 & $0.150 \pm 0.009$ & 62.74 & 62.75 & -0.02 \\
\hline$(\mathrm{LiNaK})_{2} \mathrm{CO}_{3}$ & 882 & $2.001 \pm 0.010$ & 0.50 & 9 & $0.200 \pm 0.023$ & 50.02 & 49.97 & 0.08 \\
\hline$(\mathrm{LiNaK})_{2} \mathrm{CO}_{3}$ & 986 & $1.952 \pm 0.009$ & 0.46 & 9 & $0.195 \pm 0.017$ & 51.27 & 51.20 & 0.13 \\
\hline$(\mathrm{LiNaK})_{2} \mathrm{CO}_{3}$ & 1087 & $1.907 \pm 0.006$ & 0.31 & 9 & $0.182 \pm 0.010$ & 52.48 & 52.40 & 0.16 \\
\hline$(\mathrm{LiNaK})_{2} \mathrm{CO}_{3}$ & 1158 & $1.878 \pm 0.004$ & 0.21 & 9 & $0.176 \pm 0.008$ & 53.29 & 53.24 & 0.10 \\
\hline $\mathrm{KCa}_{0.5} \mathrm{CO}_{3}$ & 1128 & $2.125 \pm 0.003$ & 0.14 & 4 & $0.158 \pm 0.010$ & 56.07 & 56.18 & -0.20 \\
\hline $\mathrm{KCa}_{0.5} \mathrm{CO}_{3}$ & 1178 & $2.103 \pm 0.002$ & 0.10 & 4 & $0.166 \pm 0.006$ & 56.66 & 56.77 & -0.20 \\
\hline $\mathrm{KCa}_{0.5} \mathrm{CO}_{3}$ & 1228 & $2.068 \pm 0.012$ & 0.58 & 12 & $0.152 \pm 0.020$ & 57.61 & 57.36 & 0.45 \\
\hline$\left(\mathrm{LiNaKCa}_{0.5}\right)_{2} \mathrm{CO}_{3}$ & 829 & $2.086 \pm 0.011$ & 0.53 & 6 & $0.189 \pm 0.019$ & 47.98 & 47.74 & 0.49 \\
\hline$\left(\mathrm{LiNaKCa}{ }_{0.5}\right)_{2} \mathrm{CO}_{3}$ & 939 & $2.044 \pm 0.003$ & 0.15 & 2 & $0.192 \pm 0.013$ & 48.96 & 48.97 & 0.00 \\
\hline$\left(\mathrm{LiNaKCa}_{0.5}\right)_{2} \mathrm{CO}_{3}$ & 1045 & $2.001 \pm 0.003$ & 0.15 & 4 & $0.181 \pm 0.011$ & 50.02 & 50.15 & -0.26 \\
\hline$\left(\mathrm{LiNaKCa} \mathrm{Ca}_{0.5}\right)_{2} \mathrm{CO}_{3}$ & 1147 & $1.960 \pm 0.004$ & 0.20 & 2 & $0.180 \pm 0.015$ & 51.06 & 51.28 & -0.43 \\
\hline
\end{tabular}

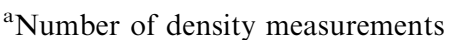


For each liquid sample, density measurements were made at two to four temperatures, spanning an interval that ranged from 52 to $318^{\circ} \mathrm{C}$ (Table 2). The lower temperature limit of the density experiments was constrained by the liquidus temperature, whereas the upper temperature limit was constrained by the decomposition temperature. Temperature was held constant for at least half an hour before each measurement to ensure that thermal equilibrium was attained within the sample. Temperature control and calibration are described in detail by Liu and Lange (2001). A check on the accuracy of our high-temperature double-bob data was obtained by measurements of the density of liquid $\mathrm{NaCl}$. Our measurements are within 0.11 and $-0.15 \%$ of the fit to the $\mathrm{NaCl}$ density data of Stein et al. (1986) and Lange and Carmichael (1987), and are within -0.45 and $-0.04 \%$ of the values recommended by NIST (Janz 1992).

For the two $\mathrm{CaCO}_{3}$-bearing samples (50 and $15 \mathrm{~mol} \%$, respectively), a steady flow of $\mathrm{CO}_{2}$ was streamed through the muffle tube of the Deltech furnace before and after immersion of the $\mathrm{Pt}$ bobs. The stream of $\mathrm{CO}_{2}$ at 1 bar stabilizes the $\mathrm{CaCO}_{3}$ component in the alkali carbonate liquids. After each bob was fully immersed in the melt, the $\mathrm{CO}_{2}$ gas was briefly turned off (for $\sim 2 \mathrm{~min}$ ) in order to steady the balance for a reading. For the alkali carbonate liquids, buoyancy measurements for a single bob were made at different temperatures during a heating cycle. The buoyancy of subsequent bobs in the same liquids at the same temperatures were measured in a similar manner. The stability of the $\mathrm{CaCO}_{3}$-bearing liquids with increasing temperature was monitored. For each of these two liquids, all bobs (small and large) were first immersed in the liquid at the lowest temperature of measurement, thus allowing between four and six density determinations to be made at this lowest temperature (Table 2). Then, after all the bobs were cleaned (during which time the furnace was brought to subsolidus temperatures), the temperature of the melt was increased to the next highest increment and the buoyancy of all bobs were measured again, allowing up to four density measurements to be made (Table 2). At the highest temperature of measurement $(1,228 \mathrm{~K})$, for the liquid with the highest concentration of $\mathrm{CaCO}_{3}(50 \mathrm{~mol} \%)$, up to 12 density measurements were made over the course of several days, and no systematic change in the density of the liquid was observed with time (Appendix 1), indicating no evidence of progressive decomposition. As an additional check, after all the density measurements were completed on the two $\mathrm{CaCO}_{3}$-bearing liquids, the resultant crystalline material was analyzed by X-ray powder diffraction. No lime $(\mathrm{CaO})$ crystals were detected in either sample, which further indicates that decomposition did not occur during the density measurements.

\section{Results}

Molar volumes were calculated for each experimental liquid at each temperature of density measurement by dividing the density into the gram formula weight (g.f.w., defined in Table 1). The density and molar volumes of the nine carbonate liquids at their respective temperatures are shown in Table 2. Fitted volume equations for each experimental liquid are given in Table 3. All of these data were used to calibrate the following linear volume equation:

$$
V^{l i q}(X, T)=\sum X_{i}\left[\bar{V}_{i, T_{\text {ref }}}+\left(T-T_{\text {ref }}\right) \partial \bar{V}_{i} / \partial T\right]
$$

where $X_{i}$ is the mole fraction of each carbonate component, and $\bar{V}_{i}$ and $\partial \bar{V}_{i} / \partial T$ are the partial molar volume and thermal expansivity of each component. Fitted values of $\bar{V}_{i}$ at $1,100 \mathrm{~K}\left(\mathrm{~T}_{\text {ref }}\right)$ and $\partial \bar{V}_{i} / \partial T$ are given in Table 4. The excellent quality of the fit is shown in the plot of residuals (measured vs. calculated volumes of the
Table 3 Fitted volume equation for each experimental liquid

\begin{tabular}{llll}
\hline$V=a_{1100 \mathrm{~K}}+\mathrm{b}(\mathrm{T}-1100) \mathrm{cm}^{3} / \mathrm{mol}$ & & \\
\hline Sample & $a_{1,100 \mathrm{~K}}$ & $b \times 10^{3}$ & Temp. range (K) \\
\hline $\mathrm{K}_{2} \mathrm{CO}_{3}$ & 71.29 & 17.58 & $1190-1242$ \\
$\mathrm{Na}_{2} \mathrm{CO}_{3}$ & 53.30 & 12.62 & $1140-1242$ \\
$\mathrm{Li}_{2} \mathrm{CO}_{3}$ & 41.17 & 7.89 & $1039-1140$ \\
$(\mathrm{NaK})_{2} \mathrm{CO}_{3}$ & 60.66 & 14.57 & $1039-1242$ \\
$\mathrm{LiKCO}$ & 56.52 & 13.93 & $882-1158$ \\
$(\mathrm{LiNa})_{2} \mathrm{CO}_{3}$ & 46.80 & 10.08 & $828-1136$ \\
$(\mathrm{LiNaK})_{2} \mathrm{CO}_{3}$ & 52.62 & 11.89 & $882-1158$ \\
$\mathrm{KCa}{ }_{0.5} \mathrm{CO}_{3}$ & 55.57 & 15.45 & $1128-1228$ \\
$\left(\mathrm{LiNaKCa} \mathrm{Ca}_{0.5}\right)_{2} \mathrm{CO}_{3}$ & 50.57 & 9.72 & $829-1147$ \\
\hline
\end{tabular}

Table 4 Fitted values for the partial molar volume and thermal expansivity of carbonate components

\begin{tabular}{lcl}
\hline$V=V_{i}(1,000 \mathrm{~K})+\partial V_{i} / \partial T(T-1,100 \mathrm{~K})$ & \\
\hline Component & $\begin{array}{l}V_{i}(1,100 \mathrm{~K}) \\
\left(\mathrm{cm}^{3} / \mathrm{mol}\right)\end{array}$ & $\begin{array}{l}\partial V_{i} / \partial T \\
\left(10^{-3} \mathrm{~cm}^{3} / \mathrm{mol}-\mathrm{K}\right)\end{array}$ \\
\hline $\mathrm{K}_{2} \mathrm{CO}_{3}$ & $71.50 \pm 0.09$ & $16.40 \pm 0.83$ \\
$\mathrm{Na}_{2} \mathrm{CO}_{3}$ & $53.20 \pm 0.08$ & $13.04 \pm 0.80$ \\
$\mathrm{Li}_{2} \mathrm{CO}_{3}$ & $41.19 \pm 0.07$ & $8.30 \pm 0.94$ \\
$\mathrm{CaCO}_{3}$ & $40.20 \pm 0.22$ & $7.15 \pm 2.23$ \\
\hline
\end{tabular}

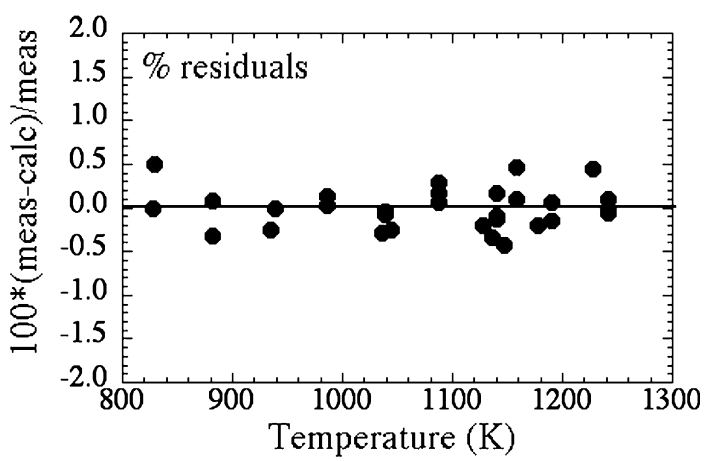

Fig. 1 The residuals $(100 \times$ (measured volume-calculated volume)/ measured volume) of all data as a function of temperature. All residuals are $\leq 0.50 \%$

experimental liquids) versus temperature (Fig. 1). The fitted values for the $\mathrm{Li}_{2} \mathrm{CO}_{3}, \mathrm{Na}_{2} \mathrm{CO}_{3}$ and $\mathrm{K}_{2} \mathrm{CO}_{3}$ components match those measured for the pure, end-member compositions (Fig. 2). The data are recovered with an average residual of $\pm 0.18 \%$ and a maximum residual $\pm 0.50 \%$, which is well within our experimental errors (0.05-0.58\%; Table 2$)$. The data points are randomly distributed around the zero line and show no structure with temperature, which demonstrates the linear dependence on both composition and temperature within the experimental resolution.

\section{Surface tension}

One of the advantages of the double-bob method presented in this study is that it allows the surface tension of 

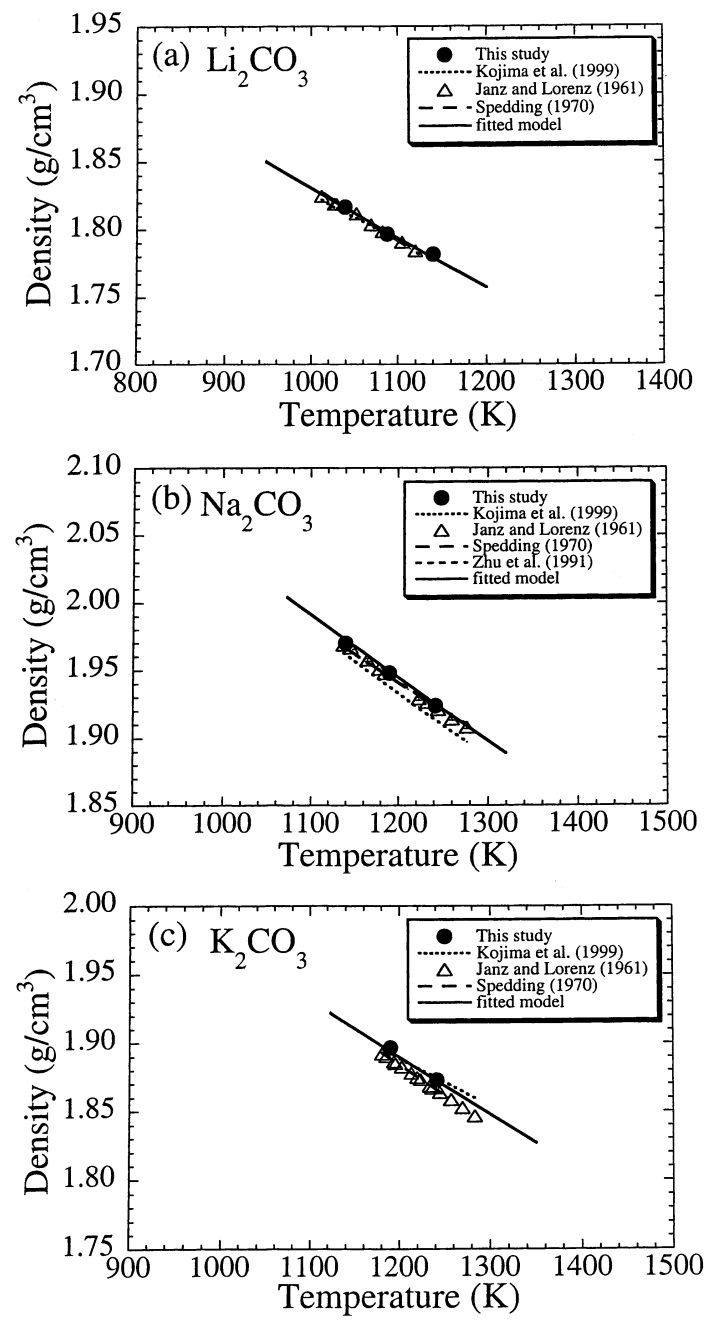

Fig. 2 Measurements of density for the pure alkali carbonate liquids, a $\mathrm{Li}_{2} \mathrm{CO}_{3}, \mathbf{b} \mathrm{Na}_{2} \mathrm{CO}_{3}$, c $\mathrm{K}_{2} \mathrm{CO}_{3}$. Density data from the literature are shown for comparison. Janz and Lorenz (1961) reported their experimental data points, whereas all other studies only reported the parameters of a linear fit to their data. Error bars from this study are either shown or are smaller than the size of the markers. Density calculated from our fitted model is shown as a solid line and extends beyond the stable liquid region (to higher and lower temperatures) for illustration

the carbonate melt on the $\mathrm{Pt}$ stem to be measured (Table 2). During immersion of each bob in the melt, the force of the liquid surface tension on the stem "pulls" on the bob; this causes the mass of the bob, while it is immersed in the liquid, to appear larger than its true value, which in turn makes the buoyancy measurement smaller than its true value. As a consequence, for the single-bob method, the effect of the surface tension must be added to the buoyancy measurement in order to calculate density; otherwise the density that is obtained is too low (too light). Thus, the appropriate equation is:

$\rho(T)=\frac{B(T)+S(T)}{V(T)}$

where $B(T)$ is the buoyancy of the single bob, $S(T)$ is the effect of surface tension of the liquid on the stem of the bob, and $V(T)$ is the immersed volume of the single bob. Equation (3) can be rearranged to allow $S(T)$ to be calculated for each bob that was used to measure the densities of our sample liquids by the double-bob method:

$S(T)=\rho^{l i q}(T) V^{b o b}(T)-B(T)$

The term $S$ has the units of mass $(\mathrm{g})$, and it can be used to calculate the surface tension, $\gamma(\mathrm{N} / \mathrm{m})$, from the following equation:

$\gamma(T)=\frac{S(T)}{\pi d} g$

where $g$ is the gravitational acceleration, and $d$ is the diameter of the stem (mm). Our measurements of $\gamma(T)$ for $\mathrm{Li}_{2} \mathrm{CO}_{3}, \mathrm{Na}_{2} \mathrm{CO}_{3}$, and $\mathrm{K}_{2} \mathrm{CO}_{3}$ (Table 2) are broadly consistent with those reported by Janz and Lorenz (1961) and Kojima et al. (1999). The surface tension data are not expected to be identical owing to the different materials that were used in the different studies (Pt vs. $\mathrm{Au}-\mathrm{Pd}$ vs. $\mathrm{Al}_{2} \mathrm{O}_{3}$ ). Nonetheless, in agreement with the conclusion drawn by Janz and Lorenz (1961), the surface tension correction on metallic stem diameters is not negligible for single-bob density measurements, even for stem diameters as thin as $0.1 \mathrm{~mm}$.

\section{The alkali carbonate liquids: comparison with previous work}

The results of our density measurements on the alkali carbonate liquids are compared to those from six previous studies (Kojima et al. 1999; Araki et al. 1987; Spedding 1970; Ward and Janz 1965; Vorob'ev et al. 1961; Janz and Lorenz 1961) in Figs. 2, 3, 4. A critical evaluation of the density data reported in the literature is necessary, because there is considerable inter-laboratory variation. Only one previous study (Janz and Lorenz 1961) measured the density of well-known liquid standards as a test of the accuracy of their method.

Of the six previous studies, one is based on the maximum bubble pressure method (Kojima et al. 1999), whereas all others are based on the single-bob Archimedean method. Although the maximum bubble pressure method gives density errors of $\sim 2 \%$ for silicate melts (Barrett and Thomas 1959), Kojima et al. (1999) report a maximum experimental error of $0.9 \%$ for the more fluid, alkali carbonate melts. Our results are within experimental error of those of Kojima et al. (1999) for the three end-member liquids (Fig. 2) and the three binary alkali liquids measured in both studies (Fig. 3).

As discussed above, the single-bob method differs from the double-bob method in that a correction for surface tension on the stem of the bob is required. The magnitude of the surface tension correction on the density measurement varies with the composition of the melt, the stem material, the stem diameter, and the density and mass of the bob. For those studies in which 

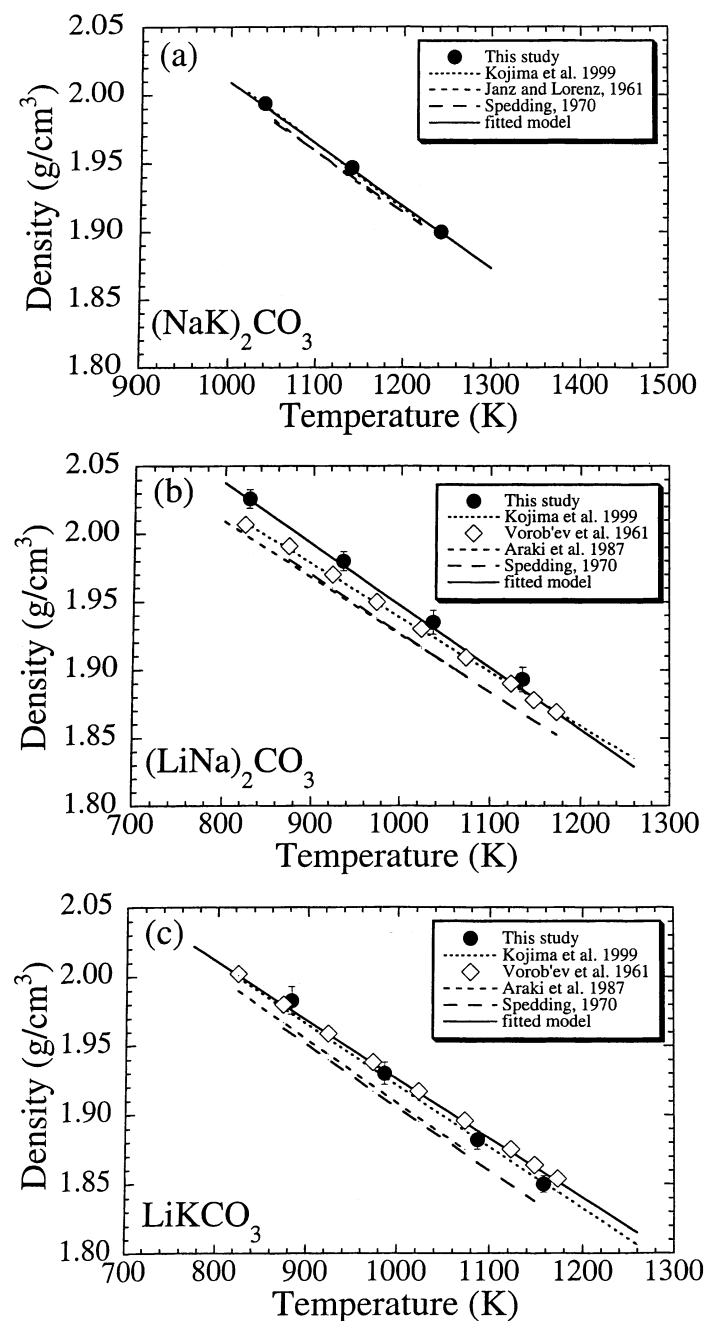

Fig. 3 Measurements of density for three binary alkali carbonate liquids, a $(\mathrm{NaK})_{2} \mathrm{CO}_{3}, \mathbf{b}(\mathrm{LiNa})_{2} \mathrm{CO}_{3}, \mathbf{c}(\mathrm{LiK})_{2} \mathrm{CO}_{3}$. Density data from the literature are shown for comparison. Vorob'ev et al. (1961) reported the experimental data points, whereas all other studies only reported the parameters of a linear fit to their data. Error bars from this study are either shown or are smaller than the size of the markers. Density calculated from our fitted model is shown as a solid line and extends beyond the stable liquid region (to higher and lower temperatures) for illustration

a stem diameter of $\sim 0.1 \mathrm{~mm}$ was used (and similar bobs as that in our study), the correction varies from $\sim 0.15$ to $\sim 0.35 \%$ in density. If bobs of smaller mass were used, the correction increases in relative magnitude. The absence of a surface tension correction (incorrectly assumed to be negligible for stem diameters of $0.1 \mathrm{~mm}$ in some studies) leads to density measurements that are systematically too low (too light).

Only four previous studies (Janz and Lorenz 1961; Spedding 1970; Zhu et al. 1991; Kojima et al. 1999) report density data on the end-member alkali carbonate liquids. Our density measurements match those of the previous studies within the reported experimental errors (Fig. 2). For the Na-K binary liquid, our density results compare well $(\leq 0.21 \%)$ to those of previous studies (Kojima et al. 1999; Spedding 1970; Janz and Lorenz
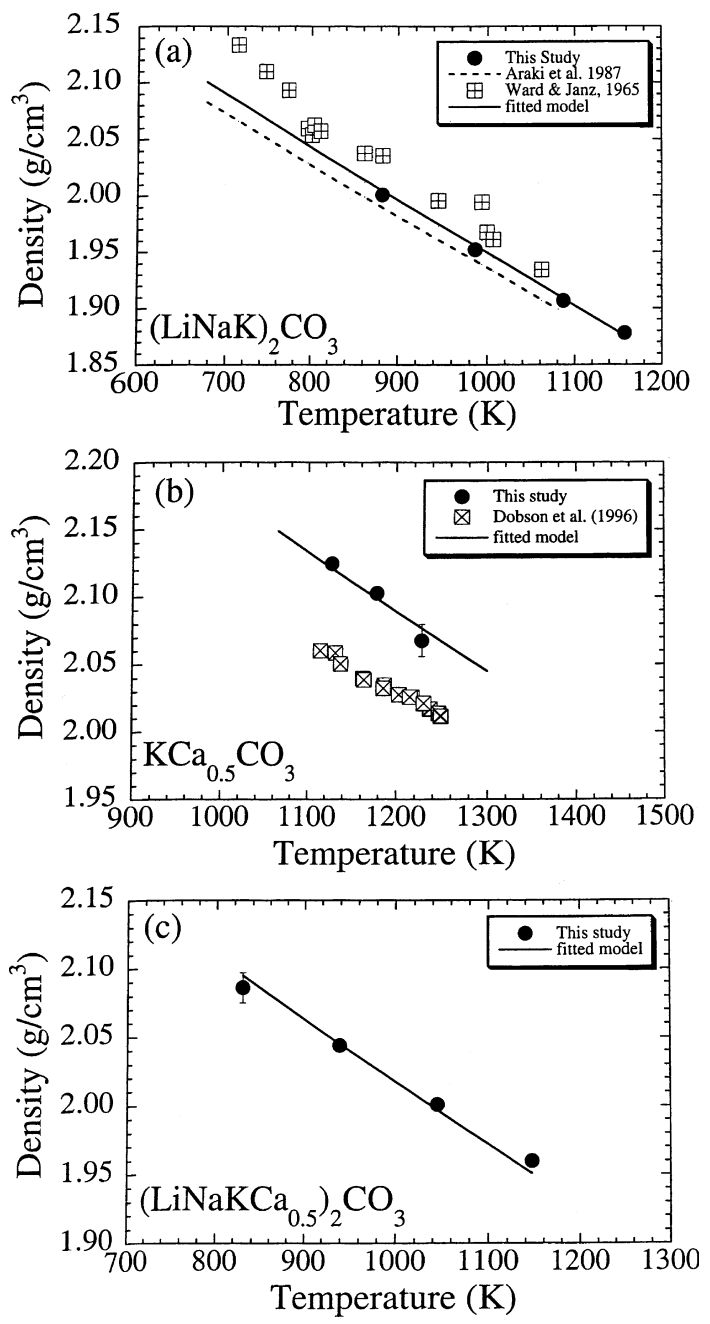

Fig. 4 Measurements of density for a ternary alkali carbonate liquid and two $\mathrm{CaCO}_{3}$-bearing liquids, a (LiNaK) ${ }_{2} \mathrm{CO}_{3}, \mathbf{b} \mathrm{KCa}_{0.5} \mathrm{CO}_{3}$, c $\left(\mathrm{LiNaKCa}_{0.5}\right)_{2} \mathrm{CO}_{3}$. Density data from the literature are shown for comparison. Ward and Janz (1965) and Dobson et al. (1996) reported the experimental data points, whereas all other studies only reported the parameters of a linear fit to their data. Error bars from this study are either shown or are smaller than the size of the markers. Density calculated from our fitted model is shown as a solid line and extends beyond the stable liquid region (to higher and lower temperatures) for illustration

1961), indicating good inter-laboratory agreement (Fig. 3a). For the two binary liquids containing $\mathrm{Li}_{2} \mathrm{CO}_{3}$, the inter-laboratory agreement is poor (Fig. 3b, c). Our density data match those from Kojima et al. (1999) and Vorob'ev et al. (1961) within reported experimental error, but are systematically higher $(\leq 1.4 \%)$ than those of Araki et al. (1987) and Spedding (1970).

A comparison of our results with Ward and Janz (1965) are the most surprising, given the excellent agreement we find with the data of Janz and Lorenz (1961). For some of our liquid compositions, the agreement is excellent (e.g., the Li-Na binary, $\leq 0.4 \%$; the lower temperature measurements for the Li-K binary, $\leq 0.4 \%$ ), but for the Li-Na-K ternary composition, the results of Ward and Janz (1965) are remarkably discrepant $(\leq 2.9 \%)$ and show considerable scatter 
(Fig. 4a). Araki et al. (1987) also measured the density of this ternary alkali liquid and give results consistent with ours (Fig. 4a). Ward and Janz (1965) measured nearly the same binary Na-K liquid as we did (the liquid compositions differ by $1 \mathrm{~mol} \%$ ), with results that are discrepant by $\leq 1.5 \%$ with all subsequent measurements, as well as the previous data of Janz and Lorenz (1961).

Two conclusions can be drawn from this comparison with previous work. First, there is considerable interlaboratory scatter among the studies that used the single-bob method to measure density. Second, our density measurements are either in excellent agreement with those of previous studies (Janz and Lorenz 1961; Vorob'ev et al. 1961; Kojima et al. 1999) or are systematically denser than those obtained by the single-bob method (where no replications were made, no correction for surface tension, and no test of accuracy against a liquid standard was performed). An exception is the data of Ward and Janz (1965) on the ternary liquid composition (Fig. 4a), which are denser than our results and show considerable scatter.

\section{The $\mathrm{CaCO}_{3}$-bearing liquids: comparison with previous work}

The results for the two $\mathrm{CaCO}_{3}$-bearing liquids are presented in Table 2 and Fig. 4b, c. Again, our measurements are well recovered $(\leq 0.5 \%)$ by our fitted multicomponent model. For the binary liquid, $\mathrm{KCa}_{0.5} \mathrm{CO}_{3}$, our density measurements can be compared to those of Dobson et al. (1996), who measured the density of this liquid with the single-bob method, using a corundum bob $(0.5 \mathrm{~g})$ with a Pd wire stem $(0.1 \mathrm{~mm})$. Surprisingly, the Dobson et al. (1996) density measurements are $\sim 3.3 \%$ lower than our results, although the slopes of the two data sets with temperature are nearly the same (Fig. 4b). This difference in density is close to an order of magnitude larger than our experimental errors.

Error analysis shows that some of this discrepancy can be attributed to the absence of a surface tension correction by Dobson et al. (1996) on their Pd stem diameter of $0.1 \mathrm{~mm}$. Given the density of corundum (3.986 $\mathrm{g}$ at $298 \mathrm{~K}$; Smyth and McCormick 1995), its thermal expansion $\left(23 \times 10^{-6} \mathrm{~K}^{-1}\right.$; Fei 1995), and the reported mass of $0.5 \mathrm{~g}$, the volume of the immersed corundum bob is calculated to be $\sim 0.128 \mathrm{~cm}^{3}$ at $930{ }^{\circ} \mathrm{C}(1,203 \mathrm{~K})$. The effect of the surface tension $(0.155 \mathrm{~N} / \mathrm{m}$; Table 2$)$ on the stem diameter at 1,203 $\mathrm{K}$ can be calculated from Eq. (4). When this value for $\mathrm{S}$ at $1,203 \mathrm{~K}(0.0016 \mathrm{~g})$ is divided by the volume of the bob at $1,203 \mathrm{~K}$, it gives a correction to the density of $\sim 0.0124 \mathrm{~g} / \mathrm{cm}^{3}$, which is $\sim 0.6 \%$ of the value reported by Dobson et al. (1996) for this liquid at $930{ }^{\circ} \mathrm{C}$ $\left(2.0278 \mathrm{~g} / \mathrm{cm}^{3}\right)$. Thus by including a surface tension correction, their calculated density would have been $\sim 0.6 \%$ higher.

This still leaves an additional $2.7 \%$ discrepancy to be accounted for, which is likely caused by the small mass of the corundum bob $(0.5 \mathrm{~g})$ used by Dobson et al. (1996) compared to the relatively large mass of the Pt bobs $(\sim 11.6$ and $\sim 26.6 \mathrm{~g})$ used in our study. Equations (1) and (3) show that the measurement of buoyancy (B: the mass of the bob in air minus the mass of the bob in liquid) is critical to the measurement of liquid density. Dobson et al. (1996) used an analytical balance with a sensitivity $\pm 0.00001 \mathrm{~g}$, but owing to gas convection within their furnace, the resultant error was $\pm 0.00010 \mathrm{~g}$ (Dobson, personal communication), which is the same uncertainty for the balance used in this study. Because of the smaller mass of bob employed by Dobson et al. (1996), error analysis on the buoyancy measurements indicates that their average experimental scatter should be more than an order of magnitude higher than ours $(\sim 2.5$ vs. $\sim 0.25 \%)$. The excellent reproducibility between the heating and cooling results of the Dobson et al. (1996) study does not preclude this assessment of their accuracy, because their data are not based on a series of independent density measurements where the bob was removed, cleaned, re-loaded, etc. Replication of the entire experimental procedure is necessary for an accurate evaluation of how much error is introduced in a single experiment; this is an exercise that we performed numerous times on the same liquid (e.g., $\mathrm{KCa}_{0.5} \mathrm{CO}_{3}$ ) at the same temperature. Moreover, their method was not tested on a liquid with a known density, such as the alkali carbonate end-members or liquid $\mathrm{NaCl}$ (a NIST standard for liquid density), as was done in this study. As a consequence, the density measurements reported here are likely to be more accurate for $\mathrm{KCa}_{0.5} \mathrm{CO}_{3}$ liquid.

\section{Linear vs. nonlinear volume of mixing}

\section{Carbonate liquids}

The model equation given in Eq. (2) for calculating the volume of carbonate liquids assumes that the $\bar{V}_{i}$ and $\partial \bar{V}_{i} / \partial T$ for each carbonate component mixes ideally. The data reported in this study support that assumption as illustrated in Fig. 1, where it shown that Eq. (2) recovers the density measurements within experimental error. The conclusion that the volumes of carbonate liquids mix ideally in composition is widely agreed upon in the literature for the Na-K binary. A plot of density measurements on three liquids along this binary $(25: 75,50: 50,75: 25)$ from Janz and Lorenz (1961), compositions not measured in this study, are recovered with high precision by our model equation (Fig. 5) and further indicate that the volumes mix ideally, at least along this binary. It is only for liquids along the Li-bearing binaries that some authors have suggested non-ideal mixing may occur. For example, Spedding (1970) argues that mixing is ideal along the Li-Na carbonate binary, but non-ideal along the Li-K carbonate binary.

However, it is clear from the examination of interlaboratory errors in the Results section that the case 


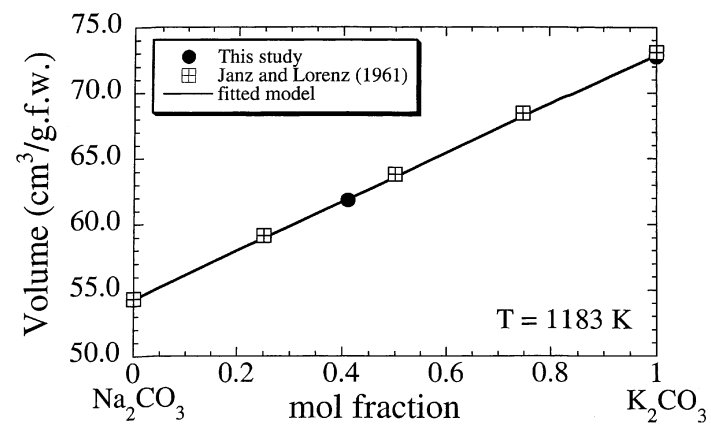

Fig. 5 The molar volume of $\mathrm{Na}_{2} \mathrm{CO}_{3}-\mathrm{K}_{2} \mathrm{CO}_{3}$ binary liquids as a function of composition. Data points are from Janz and Lorenz (1961) and this study. Density calculated from our fitted model is shown as a solid line. All data from the two studies fall on the solid line and demonstrate ideal mixing of volume

for non-ideal mixing has not been made and instead can be attributed to experimental error. The data set for which non-ideal mixing is claimed consists of measurements that were not replicated (where the bob is removed, cleaned, and re-immersed, etc.), where a liquid standard was not measured as a test of accuracy, and where a surface tension correction was not applied. Therefore, there are not yet any high-quality data to support the hypothesis that non-ideal mixing in volume occurs in carbonate liquids. Additional high-quality density measurements that expand the compositional range for carbonate liquids are needed to further test the assumption of ideal mixing in Eq. (2). In the meantime, all the measurements provided in this study are consistent with ideal mixing of the end-member carbonate liquid components, which is similar to what is found for most of the oxide components in silicate liquids.

\section{Carbonate and silicate liquids}

Lange and Carmichael (1987), Lange (1997), and Ochs and Lange (1999) showed that high-quality density measurements on silicate liquids are best described by a volume equation in which the partial molar volume and thermal expansivity of the end-member oxide components $\left(\mathrm{SiO}_{2}, \mathrm{Al}_{2} \mathrm{O}_{3}, \mathrm{FeO}, \mathrm{MgO}, \mathrm{CaO}, \mathrm{Na}_{2} \mathrm{O}, \mathrm{K}_{2} \mathrm{O}, \mathrm{H}_{2} \mathrm{O}\right)$ mix linearly in composition under the condition that all oxide components other than $\mathrm{SiO}_{2}$ are present in concentrations $\leq 50 \%$. The exception to this linear model occurs when network-forming cations (e.g., $\mathrm{Al}^{3+}, \mathrm{Fe}^{3+}$, $\left.\mathrm{Ti}^{4+}\right)$ are in variable coordination environments $(4,5$, and 6 fold) (e.g, Lange and Carmichael 1987; Dingwell and Brearley 1988; Liu and Lange 2001). In contrast, variations in the coordination (and/or speciation) of the network-modifying cations do not affect the ideal mixing of their oxide $\bar{V}_{i}$ values. Two questions now arise: do carbonate and silicate melts mix linearly in volume and what can be deduced about the partial molar volume of the $\mathrm{CO}_{2}$ component $\left(\bar{V}_{\mathrm{CO}_{2}}\right)$ in silicate liquids, when it is dissolved as carbonate.
Table 5 Fitted values for the partial molar volume and thermal expansivity of carbonate components

\begin{tabular}{lll}
\hline Component & $\begin{array}{l}\bar{V}_{\mathrm{CO}_{3}} \\
\left(\mathrm{~cm}^{3} / \mathrm{mol}\right)\end{array}$ & $\begin{array}{l}\partial \bar{V}_{\mathrm{CO}_{2}} / \partial T \\
\left(10^{-3} \mathrm{~cm}^{3} / \mathrm{mol}-\mathrm{K}\right)\end{array}$ \\
\hline $\mathrm{K}_{2} \mathrm{CO}_{3}$ & $32.35 \pm 0.09$ & $4.32 \pm 0.85$ \\
$\mathrm{Na}_{2} \mathrm{CO}_{3}$ & $28.73 \pm 0.11$ & $5.36 \pm 0.81$ \\
$\mathrm{Li}_{2} \mathrm{CO}_{3}$ & $27.69 \pm 0.15$ & $2.48 \pm 1.19$ \\
$\mathrm{CaCO}_{3}$ & $25.81 \pm 0.23$ & $3.41 \pm 2.23$ \\
\hline
\end{tabular}

Partial molar volume of oxide components from silicate volume model of Lange and Carmichael (1987) and Lange (1997)

The results of this study can be used to address these questions. When the silicate-based values for $\bar{V}_{\mathrm{CaO}}, \bar{V}_{\mathrm{Li}_{2} \mathrm{O}}, \bar{V}_{\mathrm{Na}_{2} \mathrm{O}}$, and $\bar{V}_{\mathrm{K}_{2} \mathrm{O}}$ at $1,100 \mathrm{~K}$ from Lange and Carmichael (1987) and Lange (1997) are subtracted from the values obtained in this study for $\bar{V}_{\mathrm{CaCO}_{3}}, \bar{V}_{\mathrm{Li}_{2} \mathrm{CO}_{3}}, \bar{V}_{\mathrm{Na}_{2} \mathrm{CO}_{3}}$, and $\bar{V}_{\mathrm{K}_{2} \mathrm{CO}_{3}}$ at $1100 \mathrm{~K}$, the resultant values for $\bar{V}_{\mathrm{CO}_{2}}$ are 25.8, 27.7, 28.7, and $32.4 \mathrm{~cm}^{3} / \mathrm{mol}$, respectively. There is a systematic increase in $\bar{V}_{\mathrm{CO}_{2}}$ with decreasing cation field strength. The variation in $\bar{V}_{\mathrm{CO}_{2}}$ with composition demonstrates that carbonate and silicate melts do not mix ideally in volume.

This general approach can also be used to estimate the thermal expansivity of the $\mathrm{CO}_{2}$ component $\left(\partial \bar{V}_{\mathrm{CO}_{2}} / \partial T\right)$, and the results indicate values between $3-5 \times 10^{-3} \mathrm{~cm}^{3} / \mathrm{mol}$ per $\mathrm{K}$ (Table 5). Estimates of $\partial \bar{V}_{\mathrm{CO}_{2}} / \partial P$ and $\bar{V}_{\mathrm{CO}_{2}}$ in silicate liquids are given below, but first require a discussion of compressibility.

\section{The compressibility of carbonate liquids}

In order to calculate the density of carbonate liquids at pressure, their compressibility, $\beta_{T}=-\left(1 / V_{T}\right)(\partial V / \partial P)_{T}$, must be known. The most direct method for determining the compressibility of liquids is through sound speed measurements, via the relation:

$\beta_{T}=\frac{1}{c_{T}^{2} \rho_{T}}+\frac{T \alpha_{T}^{2}}{C_{p} \rho_{T}}$

where $c$ is the sound speed $(\mathrm{m} / \mathrm{s}), \rho$ is the density of the liquid $\left(\mathrm{kg} / \mathrm{m}^{3}\right), C_{p}$ is the heat capacity $(\mathrm{J} / \mathrm{kg}-\mathrm{K}), T$ is temperature $(\mathrm{K})$ and $\alpha$ is the coefficient of thermal expansion $\left(\mathrm{K}^{-1}\right)$. The first term on the right-hand side of Eq. (6) is the adiabatic compressibility $\left(\beta_{s}\right)$, whereas the second term is typically $<1 \%$ of $\beta_{s}$. For the pure endmember liquids, $\mathrm{Li}_{2} \mathrm{CO}_{3}, \mathrm{Na}_{2} \mathrm{CO}_{3}$, and $\mathrm{K}_{2} \mathrm{CO}_{3}$, sound speed measurements (and their temperature dependence) are available from Zhu et al. (1991), the heat capacity values are derived from Rolin and Recapet (1964), and the density and thermal expansion are obtained in this study. From these combined data, values of $\beta_{T}$ (at $1100 \mathrm{~K})$ and $\partial \beta / \partial T$ are calculated and reported for each end-member alkali carbonate liquid in Table 6. Because the volume and thermal expansivity of the $\mathrm{Li}_{2} \mathrm{CO}_{3}$ component is similar to (but always larger than) that for 
Table 6 Compressibility and its temperature dependence of alkali carbonate liquids

\begin{tabular}{lllll}
\hline Sample & $\begin{array}{l}\beta_{1,100 K} \\
\left(10^{-6} \mathrm{bar}^{-1}\right)\end{array}$ & $\begin{array}{l}d \beta / \mathrm{dT} \\
\left(10^{-9} \mathrm{bar}^{-1} \mathrm{~K}^{-1}\right)\end{array}$ & $\left(d V_{i} / d P\right) 1,100 \mathrm{~K}$ & $\begin{array}{l}\left(d V_{i} / d P\right) / d T \\
\left(10^{-7} \mathrm{~cm}^{3} \mathrm{bar}^{-1} \mathrm{~K}^{-1}\right)\end{array}$ \\
\hline $\mathrm{K}_{2} \mathrm{CO}_{3}$ & 14.2 & 5.9 & -1.02 & -3.05 \\
$\mathrm{Na}_{2} \mathrm{CO}_{3}$ & 10.9 & 8.9 & -5.81 & -6.04 \\
$\mathrm{Li}_{2} \mathrm{CO}_{3}$ & 8.4 & 14.3 & -3.44 & -12.7 \\
\hline
\end{tabular}

the $\mathrm{CaCO}_{3}$ component (Table 4), the best estimate of the maximum value of $\beta_{T}$ for the $\mathrm{CaCO}_{3}$ component is that for $\mathrm{Li}_{2} \mathrm{CO}_{3}$. This maximum value $\left(8.4 \times 10^{-6} \mathrm{bar}^{-1}\right)$ is broadly consistent with that extrapolated to 1 bar and $1100 \mathrm{~K}\left(9.9 \times 10^{-6} \mathrm{bar}^{-1}\right)$ from the molecular dynamic simulations of Genge et al. (1995) at 1700-1900 K and $1-100$ kbar.

Values for the compressibility of the alkali carbonate liquids, combined with an estimate of the maximum compressibility for the $\mathrm{CaCO}_{3}$ component, allow the density of natrocarbonatite liquids, such as those erupted from Oldoinyo Lengai volcano in east Africa, to be calculated and compared with the density of alkaline silicate melts. In Fig. 6, the density of an olivine nephelinite liquid at $1,200{ }^{\circ} \mathrm{C}$, a phonolite liquid at $1000^{\circ} \mathrm{C}$, and a natrocarbonate liquid from Oldoinyo Lengai at $800{ }^{\circ} \mathrm{C}$ are plotted as a function of pressure. The natrocarbonate liquid is composed of $\sim 56 \mathrm{~mol} \%$ $\begin{array}{lllll}\mathrm{Na}_{2} \mathrm{CO}_{3}, \sim 36 \mathrm{~mol} \% & \mathrm{CaCO}_{3} \text { and } \sim 8 \mathrm{~mol} \% & \mathrm{~K}_{2} \mathrm{CO}_{3}\end{array}$ (erupted in September 1992; Church and Jones 1995). Also shown in Fig. 6 is the density of the pure $\mathrm{CaCO}_{3}$ liquid component at $800{ }^{\circ} \mathrm{C}$, which is slightly denser than a phonolite liquid at $1000{ }^{\circ} \mathrm{C}$. This result is broadly consistent with the experimental evidence from an experimental charge presented by Brooker and Hamilton (1990) that nearly pure $\mathrm{CaCO}_{3}$ liquid is more dense than a synthetic alkaline silicate melt at $1.5 \mathrm{GPa}$. Although the compressibility of the natrocarbonate liquid is greater than that of the phonolite liquid, which in turn is greater than that of the olivine nephelinite liquid, the density vs. pressure curves are broadly parallel to $10 \mathrm{kbar}$, and the natrocarbonate liquid remains strongly buoyant relative to the silicate magmatic liquids over crustal depths.

\section{Estimates of $\overline{\mathbf{V}}_{\mathrm{CO}_{2}}$ in alkaline silicate liquids}

Brooker et al. (2001a, 2001b) show that $\mathrm{CO}_{2}$ is present entirely as the carbonate species in strongly silicaundersaturated melts and is most strongly associated with calcium. Therefore, it is possible that the most appropriate value for $\bar{V}_{\mathrm{CO}_{2}}$ in alkaline silicate melts is that derived from the $\mathrm{CaCO}_{3}$ component above. From the estimate of $\beta_{T}$ for the $\mathrm{CaCO}_{3}$ component, the maximum compressibility of the $\mathrm{CO}_{2}$ component dissolved in alkaline silicate melts (as carbonate in close association with $\mathrm{Ca}$ ) can be estimated. When the value of $\beta_{T}$ for the $\mathrm{CaO}$ component at $1673 \mathrm{~K}$ (essentially zero; Kress and Carmichael 1991) is subtracted from the value of $\beta_{T}$ for $\mathrm{Li}_{2} \mathrm{CO}_{3}$ at $1673 \mathrm{~K}$, the result $\left(16.6 \times 10^{-6}\right.$ bars $\left.^{-1}\right)$ is our best estimate of the maximum value for the

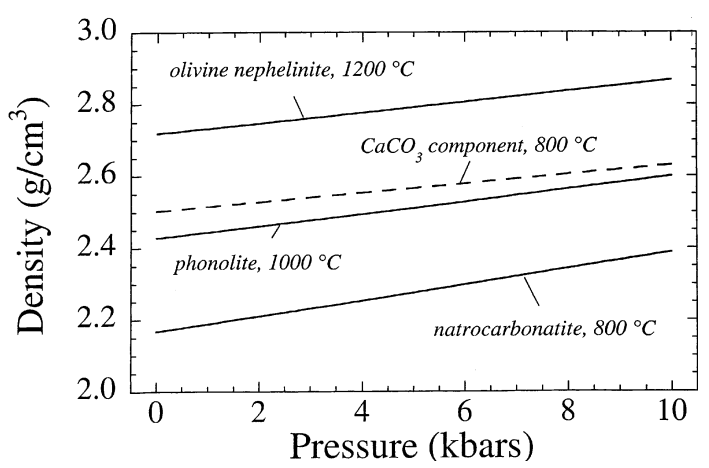

Fig. 6 A comparison of the density of olivine nephelinite liquid, phonolite liquid, natrocarbonatite liquid and the $\mathrm{CaCO}_{3}$ liquid component as a function of pressure. The silicate compositions are from Carmichael et al. (1974), whereas the natrocarbonatite composition is from Church and Jones (1995)

compressibility of the $\mathrm{CO}_{2}$ component at $1400{ }^{\circ} \mathrm{C}$ in alkaline silicate melts, when it is dissolved entirely as carbonate in close association with $\mathrm{Ca}$. When this maximum value is applied to $2 \mathrm{GPa}$, it leads to a minimum value of $\bar{V}_{\mathrm{CO}_{2}}$ of $19.9 \mathrm{~cm}^{3} / \mathrm{mol}$ at $1400{ }^{\circ} \mathrm{C}$. Because the effect of pressure on reducing the one-bar compressibility has not been taken into account, this estimate of $\bar{V}_{\mathrm{CO}_{2}}$ is clearly a minimum value at $2 \mathrm{GPa}$ and $1400{ }^{\circ} \mathrm{C}$. Thus the maximum density of the $\mathrm{CO}_{2}$ component at $1400{ }^{\circ} \mathrm{C}$ and $2 \mathrm{GPa}$ is $\sim 2.21 \mathrm{~g} / \mathrm{cm}^{3}$, which makes it a relatively buoyant component in alkaline silicate magmas at this pressure.

This estimate of $\bar{V}_{\mathrm{CO}_{2}}$ in alkaline silicate melts can be compared to those derived from thermodynamic analysis of $\mathrm{CO}_{2}$ solubility curves for silicate liquids where $\mathrm{CO}_{2}$ is dissolved entirely as carbonate (and not molecular $\mathrm{CO}_{2}$ ). The results lead to estimates of $\bar{V}_{\mathrm{CO}_{2}}$ that vary from $23-28 \mathrm{~cm}^{3} / \mathrm{mol}$ (depending on the equation of state for $\mathrm{CO}_{2}$ fluid that is used) in tholeiitic basalt liquid from 1-2 GPa at $1,400{ }^{\circ} \mathrm{C}$ (Stolper and Holloway 1988; Pan et al. 1991), and $\sim 21.5 \mathrm{~cm}^{3} / \mathrm{mol}$ in a Ca-rich leucitite liquid from $0.5-2 \mathrm{GPa}$ at $1400{ }^{\circ} \mathrm{C}$ (Thibault and Holloway 1994). The absence of direct density measurements on $\mathrm{CO}_{2}$-bearing silicate liquids precludes a comparison to $\bar{V}_{\mathrm{CO}_{2}}$ derived from such a data set. Nonetheless, the similarity between our estimate of $\bar{V}_{\mathrm{CO}_{2}}$ and those derived from the solubility curves is encouraging.

\section{Fusion curve calculations for $\mathrm{Li}_{2} \mathrm{CO}_{3}, \mathrm{Na}_{2} \mathrm{CO}_{3}$, and $\mathrm{K}_{2} \mathrm{CO}_{3}$ to 5 kbar}

Another application of the volumetric properties of carbonate liquids is calculation of crystal-liquid equilibria to 
high pressure. For example, thermodynamic modeling of the immiscibility between alkaline silicate melts and carbonate melts requires information on the volume, thermal expansion, and compressibility of the respective liquids. Although an exploration of immiscibility and other phase relations is beyond the scope of this study, the data presented here allow a preliminary step to be taken, namely calculation of the fusion curves of each of the three alkali carbonates to $5 \mathrm{kbar}$. Calculations to higher pressures cannot be made at the present time because the pressure dependence to the compressibility of these carbonate melts is not yet known. Nor can the fusion curves for $\mathrm{CaCO}_{3}$ be calculated owing to the absence of heat of fusion data for this phase. In the meantime, it is instructive to calculate the fusion curves for the three alkali carbonates and compare them to phase-equilibrium experiments on the melting reactions.

The equation used to calculate crystal-liquid equilibria as a function of temperature and pressure is:

$$
\begin{aligned}
\Delta H_{T_{f}} & +\int_{T_{f}}^{T} \Delta C_{P}(T) d T-T\left(\Delta S_{T_{f}}+\int_{T_{f}}^{T} \frac{\Delta C_{P}(T)}{T} d T\right) \\
& =-\int_{1}^{P} \Delta V_{T}(P) d P
\end{aligned}
$$

where $T_{f}$ is the one-bar melting temperature of crystalline carbonates, $\Delta H_{T_{f}}$ is the enthalpy of fusion at $T_{f}, \Delta S_{T_{f}}$ is the entropy of fusion at $T_{f}, \Delta C_{P}(T)$ is the heat capacity of the liquid minus that of the solid, $\Delta V_{T}(P)$ is the volume of the liquid minus that of the solid. The requisite data needed to calculate each fusion curve include the melting temperature at 1 bar, the enthalpy of fusion at 1 bar (from which the entropy of fusion is calculated), and the heat capacity of the crystal and liquid. These calorimetric data are summarized in Table 7 and are derived from the drop calorimetric measurements of Rolin and Recapet (1964), given the one-bar melting temperatures of 723,851 , and $891{ }^{\circ} \mathrm{C}$, respectively, for $\mathrm{Li}_{2} \mathrm{CO}_{3}, \mathrm{Na}_{2} \mathrm{CO}_{3}$ and $\mathrm{K}_{2} \mathrm{CO}_{3}$. Also needed are the volume, thermal expansion, and compressibility of the respective crystals and liquids. The liquid volumetric data are obtained from this study, whereas the crystalline volumetric data are summarized below.

For $\mathrm{Li}_{2} \mathrm{CO}_{3}$, a single polymorph is stable between room temperature and the melting point at 1 bar. The volume and thermal expansion of crystalline $\mathrm{Li}_{2} \mathrm{CO}_{3}$ at 1 bar were studied by A. Kirfel and B. Barbier with the

Table 7 Calorimetric data for $\mathrm{Li}_{2} \mathrm{CO}_{3}, \mathrm{Na}_{2} \mathrm{CO}_{3}$, and $\mathrm{K}_{2} \mathrm{CO}_{3}{ }^{\mathrm{a}}$

\begin{tabular}{llllll}
\hline Sample & $\begin{array}{l}T_{f} \\
(\mathrm{~K})\end{array}$ & $\begin{array}{l}\Delta H_{T_{f}} \\
(\mathrm{~kJ} / \mathrm{mol})\end{array}$ & $\begin{array}{l}\Delta S_{T_{f}} \\
(\mathrm{~J} / \mathrm{mol}-\mathrm{K})\end{array}$ & $\begin{array}{l}\Delta C_{P}\left(T_{f}\right) \\
(\mathrm{J} / \mathrm{mol}-\mathrm{K})\end{array}$ & $\begin{array}{l}C_{P}^{\text {liq }} \\
(\mathrm{J} / \mathrm{mol}-\mathrm{K})\end{array}$ \\
\hline $\mathrm{K}_{2} \mathrm{CO}_{3}$ & 1164 & 27.04 & 23.23 & 35.6 & 231 \\
$\mathrm{Na}_{2} \mathrm{CO}_{3}$ & 1124 & 27.64 & 24.59 & 43.9 & 199 \\
$\mathrm{Li}_{2} \mathrm{CO}_{3}$ & 996 & 35.76 & 35.90 & 94.4 & 297 \\
\hline
\end{tabular}

${ }^{a}$ Data derived from data of Rolin and Recapet (1964) single-crystal X-ray diffraction method (unpublished data). The volume equation as a function of $\mathrm{T}(\mathrm{K})$ for $\mathrm{Li}_{2} \mathrm{CO}_{3}$ at 1 bar is:

$$
\begin{aligned}
V(T)_{L_{2} \mathrm{CO}_{3}}= & 234.338+0.01003 T+9.5658 \\
& \times 10^{-6} T^{2} \mathrm{~cm}^{3} / \mathrm{mol}
\end{aligned}
$$

For $\mathrm{Na}_{2} \mathrm{CO}_{3}$, the high-temperature polymorph is hexagonal $\alpha-\mathrm{Na}_{2} \mathrm{CO}_{3}$. X-ray diffraction experiments of Brouns et al. (1964) and Tuinstra (1986) lead to the following volume equation as a function of $\mathrm{T}(\mathrm{K})$ for $\mathrm{Na}_{2} \mathrm{CO}_{3}$ at 1 bar:

$V(T)_{\mathrm{Na}_{2} \mathrm{CO}_{3}}=48.008 \exp \left[16 \times 10^{-5}(T-1063)\right]$

For $\mathrm{K}_{2} \mathrm{CO}_{3}$, the high-temperature polymorph is hexagonal $\alpha-\mathrm{K}_{2} \mathrm{CO}_{3}$. High-temperature X-ray diffraction experiments by Schneider and Levin (1973) lead to the following volume equation for $\alpha-\mathrm{K}_{2} \mathrm{CO}_{3}$ as a function of $\mathrm{T}(\mathrm{K})$ at 1 bar:

$V(T)_{K_{2} \mathrm{CO}_{3}}=64.248+0.0095(T-1078)$

Unfortunately, there are no published data on the compressibility of the crystalline alkali carbonates. However, S. Redfern has computed their compressibility using a static lattice simulation. The bulk moduli from his simulations are 70,60 , and $45 \mathrm{GPa}$ for $\mathrm{Li}_{2} \mathrm{CO}_{3}$, $\mathrm{Na}_{2} \mathrm{CO}_{3}$, and $\mathrm{K}_{2} \mathrm{CO}_{3}$, respectively (S. Redfern, personal communication). Uncertainties of $\leq 25 \%$ in these bulk moduli estimates lead to negligible errors in the calculated temperatures of the respective fusion curves at pressures $\leq 5 \mathrm{kbar}$.

There have been two experimental determinations of the melting reactions of the end-member alkali carbonates by differential thermal analysis (DTA). The first study was performed by Koster van Groos and Wyllie (1966) on $\mathrm{Na}_{2} \mathrm{CO}_{3}$ to 1 kbar in a cold-seal pressure vessel. The second study was performed by Klement and Cohen (1975) on $\mathrm{Li}_{2} \mathrm{CO}_{3}$ to $7 \mathrm{kbar}$ and on $\mathrm{K}_{2} \mathrm{CO}_{3}$ to $4.5 \mathrm{kbar}$ in an internally-heated pressure vessel. The experimental results are plotted together with the calculated fusion curves in Fig. 7. The calculated fusion curves for $\mathrm{Li}_{2} \mathrm{CO}_{3}, \mathrm{Na}_{2} \mathrm{CO}_{3}$, and $\mathrm{K}_{2} \mathrm{CO}_{3}$ are in excellent agreement with the experimental results, although there are only data up to $1 \mathrm{kbar}$ for the $\mathrm{Na}_{2} \mathrm{CO}_{3}$ melting reaction. The agreement between the calculated fusion curves and those determined experimentally by DTA indicates the internal consistency between four independent sets of experiments: (1) the calorimetric data, (2) the liquid volume data, (3) the crystalline volume data, and (4) the DTA determinations of the melting reactions at pressure and temperature. This internal consistency greatly increases the confidence in all four data sets.

\section{The density of $\mathrm{K}_{2} \mathrm{CO}_{3}$ liquid to $\mathbf{4 0}$ kbar}

An evaluation of how the compressibility of $\mathrm{K}_{2} \mathrm{CO}_{3}$ liquid varies with pressure can be made by comparing 


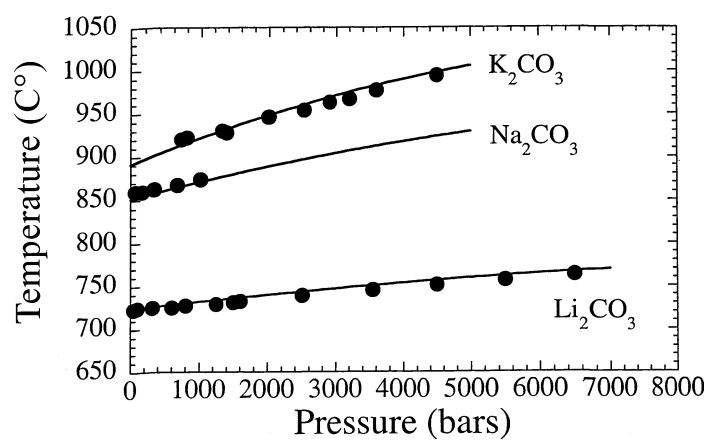

Fig. 7 The calculated fusion curves (solid lines) of $\mathrm{K}_{2} \mathrm{CO}_{3}$ and $\mathrm{Na}_{2} \mathrm{CO}_{3}$ to 5 kbar and $\mathrm{Li}_{2} \mathrm{CO}_{3}$ up to 7 kbar from Eq. (8). The solid circles are the experimentally-determined (DTA) temperatures and pressures of the respective melting reactions: $\mathrm{Li}_{2} \mathrm{CO}_{3}$ and $\mathrm{K}_{2} \mathrm{CO}_{3}$ from Klement and Cohen (1975) and $\mathrm{Na}_{2} \mathrm{CO}_{3}$ from Koster van Groos and Wyllie (1966)

the experimentally determined density of this liquid at $40 \mathrm{kbar}$ and $1500{ }^{\circ} \mathrm{C}$ (Dobson et al. 1996) with a calculation of the liquid density using the 1-bar value from this study, the compressibility at 1 bar derived from the sound speed data of Zhu et al. (1991), and an appropriate equation of state. Dobson et al. (1996) employed the falling sphere method to derive the viscosity and density of $\mathrm{K}_{2} \mathrm{CO}_{3}$ liquid at $40 \mathrm{kbar}$ and $1,500{ }^{\circ} \mathrm{C}$ using an in-situ $\mathrm{X}$-ray shadowgraph technique in a multi-anvil press. The derived density for $\mathrm{K}_{2} \mathrm{CO}_{3}$ liquid at $1500{ }^{\circ} \mathrm{C}$ and $4 \mathrm{GPa}$ is reported to be $3.10 \mathrm{~g} / \mathrm{cm}^{3}$ (Dobson et al. 1996), which is remarkably dense.

This experimentally-determined density at $40 \mathrm{kbar}$ can be compared to a series of calculated $\mathrm{K}_{2} \mathrm{CO}_{3}$ liquid density curves with pressure that are based on different equations of state for the liquid (Fig. 8). One possibility is to assume that the one-bar compressibility of $\mathrm{K}_{2} \mathrm{CO}_{3}$ liquid at $1500{ }^{\circ} \mathrm{C}$ remains constant and does not decrease with increasing pressure. The resultant density vs. pressure curve is shown as a dashed line in Fig. 8. Alternatively, the 3rd-order Birch-Murnaghan (B-M) equation of state can be employed, which is a truncated series expansion derived from finite strain theory of solids (Birch 1978). The third-order form is:

$P=\frac{3}{2} K_{T, 0}\left(R^{7 / 3}-R^{5 / 3}\right)\left[1-\frac{3}{4}\left(4-K_{0}^{\prime}\right)\left(R^{2 / 3}-1\right)\right]$

where $R=V_{T, 0} / V_{T, P}, V_{T, 0}$ is the volume at temperature and zero pressure (1 bar), $V_{T P}$ is the volume at temperature and pressure, $K_{T, 0}\left(=1 / \beta_{T, 0}\right)$ is the bulk modulus at temperature and zero pressure, and $\mathrm{K}_{0}{ }^{\prime}\left(=\mathrm{dK}_{0} /\right.$ $\mathrm{dP}$ ) is the pressure dependence of $K_{T, 0}$. The 3 rd-order B$M$ equation has empirically been shown to model the volume of silicate liquids to high pressure (tens of $\mathrm{GPa}$ ) remarkably well (e.g., Rigden et al. 1989; Stixrude and Bukowinski 1990). In Fig. 8, a family of density vs. pressure curves are shown for different values of $\mathrm{K}_{0}$, ranging from 2.55 to 14 . Also shown as a dotted line in Fig. 8 is the density vs. pressure curve for crystalline

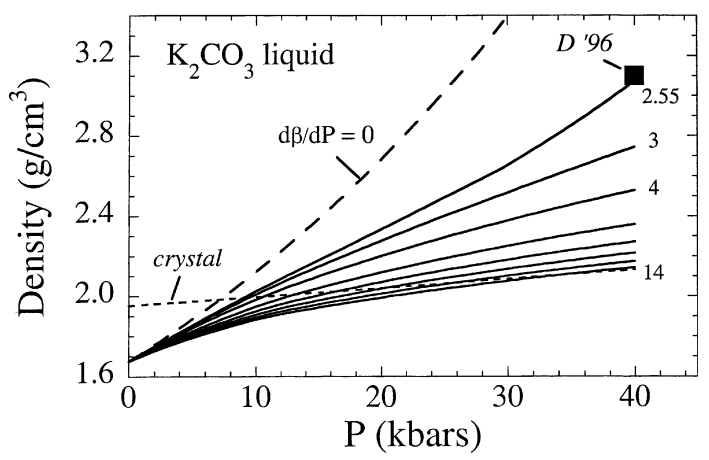

Fig. 8 Density of $\mathrm{K}_{2} \mathrm{CO}_{3}$ liquid as a function of pressure at $1500{ }^{\circ} \mathrm{C}$. The solid lines are calculated with the one-bar density and compressibility data (this study and Zhu et al. 1991) and a 3rdorder Birch-Murnaghan equation of state for different $\mathrm{K}_{0}$ ' values (2.55-14). The dashed line assumes no pressure dependence to the one-bar melt compressibility. The dotted line is the density of crystalline $\mathrm{K}_{2} \mathrm{CO}_{3}$ (extrapolated to $1500{ }^{\circ} \mathrm{C}$ ) as a function of pressure. The solid square is the reported liquid density from Dobson et al. (1996)

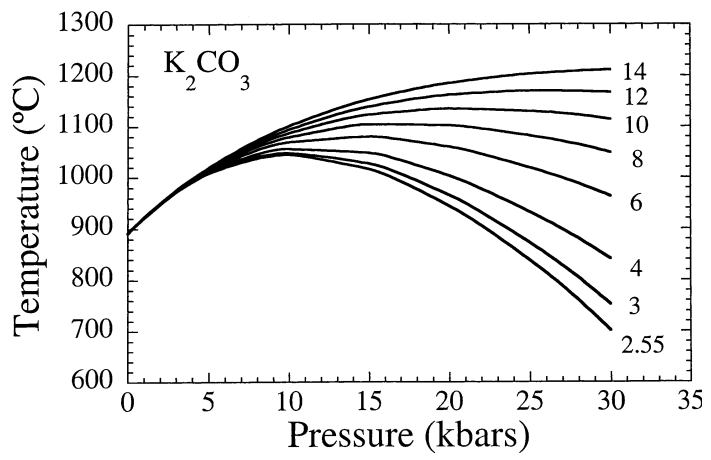

Fig. 9 The calculated fusion curves of $\mathrm{K}_{2} \mathrm{CO}_{3}$ to $30 \mathrm{kbars}$ for various values of $\mathrm{K}_{0}{ }^{\prime}$ for the liquid (shown next to each curve). The third-order Birch-Murnaghan relation is used to calculate the volume of liquid $\mathrm{K}_{2} \mathrm{CO}_{3}$ to high pressure

$\mathrm{K}_{2} \mathrm{CO}_{3}$. Note that the liquid will become more dense than the crystal by $\sim 10 \mathrm{kbar}$, if the density of Dobson et al. (1996) at $40 \mathrm{kbar}$ is correct. Alternatively, a crossover in density between the liquid and crystal is only avoided when the liquid $\mathrm{K}_{0}$ ' values are $\geq 14$ (utilizing the B-M equation of state).

The results of this analysis indicate that the reported density for $\mathrm{K}_{2} \mathrm{CO}_{3}$ liquid at $40 \mathrm{kbar}$ by Dobson et al. (1996) is consistent with a $\mathrm{K}_{0}$ ' value of 2.55 using the B-M equation of state. An independent evaluation of the density for $\mathrm{K}_{2} \mathrm{CO}_{3}$ liquid at high pressure can be obtained from phase equilibrium experiments on the melting reaction to $30 \mathrm{kbar}$, as illustrated in Fig. 9, which are not yet available in the literature. Here it is seen that the calculated temperature of the fusion curve to $30 \mathrm{kbar}$ is strongly dependent on the value of $\mathrm{K}_{0}$ ' for the liquid that is employed in the B-M equation (see Lange 2003 for a detailed discussion of this calculation). If the density measurement of Dobson et al. (1996) is correct, then the fusion curve should turn over and have a strongly negative $\mathrm{dT} / \mathrm{dP}$ slope at pressures $>10 \mathrm{kbar}$. 
If the density reported by Dobson et al. (1996) for $\mathrm{K}_{2} \mathrm{CO}_{3}$ liquid at $40 \mathrm{kbar}$ is verified, then this has significant implications for the stability of carbonate liquids at high pressure (i.e., stable to remarkably low temperatures). It also suggests that carbonate melts are much more compressible than silicate melts at pressure and are thus expected to become more dense than silicate melts at mantle depths, which has profound implications for the migration of highly incompatible trace elements that are transported by carbonate melts in the mantle. However, because the falling sphere method is not optimal for density measurements (though suitable for viscosity measurements; see Lange and Carmichael 1990 for a discussion), it is of interest to obtain an independent constraint on the density of $\mathrm{K}_{2} \mathrm{CO}_{3}$ liquid with pressure, which is readily achieved from phase-equilibrium experiments on the melting reaction to $30 \mathrm{kbar}$.

\section{Future studies}

There is considerable opportunity to further expand the volumetric data set for carbonate liquids. Double-bob density measurements at 1 bar on additional $\mathrm{CaCO}_{3}$ bearing alkali carbonate liquids will likely reduce the error on the partial molar volume and thermal expansivity of the $\mathrm{CaCO}_{3}$ component. Extension of such measurements to compositions with $\mathrm{MgCO}_{3}$-bearing alkali carbonate liquids will allow estimates of
$\bar{V}_{\mathrm{MqCO}_{3}}$ and $\partial \bar{V}_{\mathrm{MqCO}_{3} / \partial T}$ to become available. The introduction of fluorine, chlorine, phosphorus, and water into experimental liquids will allow density calculations of naturally occurring carbonatite liquids to be more precise. Subsequent sound speed measurements on these carbonatite liquids will allow direct determination of the one-bar compressibility of these components in carbonatite liquids. Finally, phase equilibrium experiments on the melting reaction of the alkali carbonates to $30 \mathrm{kbar}$ will allow a rigorous test of whether or not carbonate melts are so compressible that they are expected to become more dense than silicate melts at mantle pressures.

Acknowledgements This research was supported by the National Science Foundation (EAR-9508133 and EAR-0087764). We wish to thank A. Kirfel and B. Barbier (Mineralogisch-Petrologisches Institut, Universität Bonn, Germany) for sharing their unpublished single-crystal $\mathrm{X}$-ray diffraction data on the volume and thermal expansion of crystalline $\mathrm{Li}_{2} \mathrm{CO}_{3}$ at 1 bar. We especially thank Dr. D. Dobson for his e-mail correspondence, which helped us in our design of our density measurements of the $\mathrm{CaCO}_{3}$-bearing liquids under a stream of $\mathrm{CO}_{2}$. Helpful comments from D. Dobson, J. Wolff, and an anonymous reviewer significantly improved the manuscript.

\section{Appendix}

Table 8 shows the density of the experimental liquids.

Table 8 Density of the experimental liquids

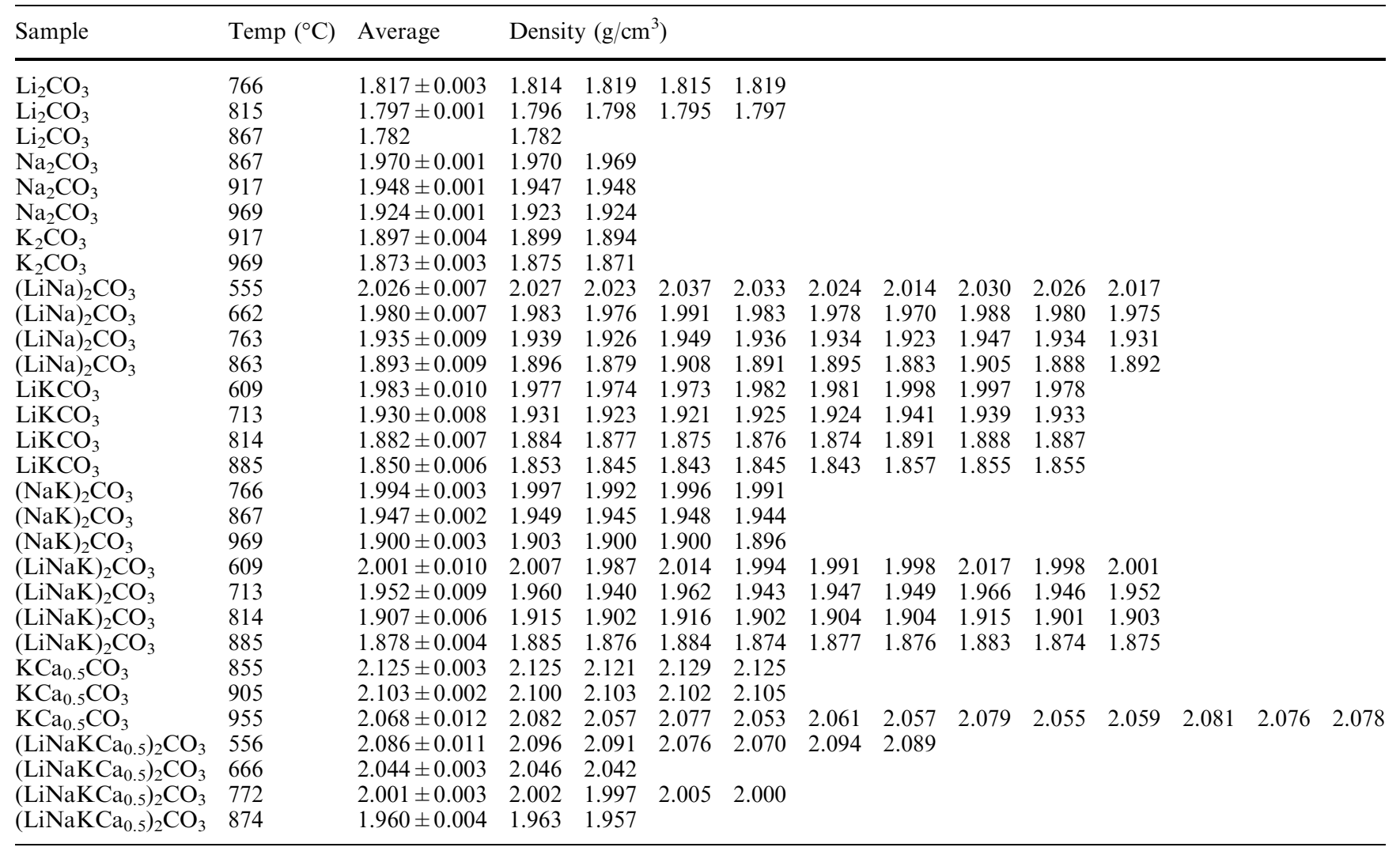




\section{References}

Araki N, Matsuura M, Makino A, Hirata T, Kato Y (1987) Measurements of thermophysical properties of molten salts (mixtures of alkaline carbonate salts). P1-4, In: 8th Japan Symposium on Thermophysical Properties

Barrett LR, Thomas AG (1959) Surface tension and density measurements on molten glasses in the $\mathrm{CaO}-\mathrm{Al}_{2} \mathrm{O}_{3}$ system. Soc Glass Tech J 43:179T-190T

Birch F (1978) Finite strain isotherm and velocities for singlecrystal and polycrystalline $\mathrm{NaCl}$ at high-pressures and 300-degree-K. J Geophys Res 83:1257-1268

Brooker RA, Hamilton DL (1990) Three-liquid immiscibility and the origin of carbonatites. Nature 346:459-462

Brooker RA, Kohn SC, Holloway JR, McMillan PF (2001a) Structural controls on the solubility of $\mathrm{CO}_{2}$ in silicate melts. Part I: bulk solubility data. Chem Geol 174:225-239

Brooker RA, Kohn SC, Holloway JR, McMillan PF (2001b) Structural controls on the solubility of $\mathrm{CO}_{2}$ in silicate melts. Part II: IR characteristics of carbonate groups in silicate glasses. Chem Geol 174:241-254

Brouns E, Visser JW (1964) An anomaly in the crystal structure of $\mathrm{Na}_{2} \mathrm{CO}_{3}$. Acta Crystallogr 17:614

Carmichael ISE, Turner FJ, Verhoogen J (1974) Igneous petrology. McGraw-Hill, New York, 739 pp

Church AA, Jones AP (1995) Silicate-carbonate immiscibility at Oldoinyo Lengai. J Petrol 36:869-889

Dingwell DB, Brearley M (1988) Melt densities in the $\mathrm{CaO}-\mathrm{FeO}-$ $\mathrm{Fe}_{2} \mathrm{O}_{3}-\mathrm{SiO}_{2}$ system and the compositional dependence of the partial molar volume of ferric iron in silicate melts. Geochim Cosmochim Acta 52:2815-2825

Dobson DP, Jones AP, Rabe R, Toshimori S, Kurita K, Taniguchi T, Kondo T, Kato T, Shimomura O, Urakawa S (1996) In-situ measurement of viscosity and density of carbonate melts at high pressure. Earth Planet Sci Lett 143:207-215

Fei Y (1995) Thermal expansion. In: Ahren T (ed) Mineral physics and crystallography. AGU Reference Shelf 2, Washington, DC pp 29-44

Genge MJ, Price GD, Jones AP (1995) Molecular dynamics simulations of $\mathrm{CaCO}_{3}$ melts to mantle pressures and temperatures: implications for carbonatite magmas. Earth Planet Sci Lett 131:225-238

Janz GJ (1992) NIST properties of molten salts database. Version 2 , Single salts and salt mixtures database, density, viscosity, electrical conductance, and surface tension. NIST Standard Reference Database 27

Janz GJ, Lorenz MR (1961) Molten carbonate electrolytes-physical properties, structure, and mechanism of electrical conductance. J Electrochem Soc 108:1052-1058

Klement W, Cohen LH (1975) Solid-solid and solid-liquid transitions in $\mathrm{K}_{2} \mathrm{CO}_{3}, \mathrm{Na}_{2} \mathrm{CO}_{3}$ and $\mathrm{Li}_{2} \mathrm{CO}_{3}$ : investigations to greater than $\geq 5$ kbar by differential thermal-analysis - thermodynamics and structural correlations. Ber Bunsen Phys Chem 79:327-334

Kojima T, Yanagida M, Tanimoto K, Tamiya Y, Matsumoto H, Miyazaki Y (1999) The surface tension and the density of molten binary alkali carbonate systems. Electrochemistry 67:593-602

Koster van Groos AF, Wyllie PJ (1966) Liquid immiscibility in the system $\mathrm{Na}_{2} \mathrm{O}-\mathrm{Al}_{2} \mathrm{O}_{3}-\mathrm{SiO}_{2}-\mathrm{CO}_{2}$ at pressures to 1 kilobar. Am J Sci 264:234-255

Kress VC, Carmichael ISE (1991) The compressibility of silicate liquids containing $\mathrm{Fe}_{2} \mathrm{O}_{3}$ and the effect of composition, temperature, oxygen fugacity and pressure on their redox states. Contrib Mineral Petrol 108:82-92

Lange RA (1997) A revised model for the density and thermal expansivity of $\mathrm{K}_{2} \mathrm{O}-\mathrm{Na}_{2} \mathrm{O}-\mathrm{CaO}-\mathrm{MgO}-\mathrm{Al}_{2} \mathrm{O}_{3}-\mathrm{SiO}_{2}$ liquids from 700 to $1,900 \mathrm{~K}$ : extension to crustal magmatic temperatures. Contrib Mineral Petrol 130:1-11

Lange (2003) The fusion curve of albite revisited and the compressibility of $\mathrm{NaAlSi}_{3} \mathrm{O}_{8}$ liquid with pressure. Am Mineral 88:109-120

Lange RA, Carmichael ISE (1987) Densities of $\mathrm{Na}_{2} \mathrm{O}-\mathrm{K}_{2} \mathrm{O}-\mathrm{CaO}$ $\mathrm{MgO}-\mathrm{FeO}-\mathrm{Fe}_{2} \mathrm{O}_{3}-\mathrm{TiO}_{2}-\mathrm{SiO}_{2}$ liquids: new measurements and derived partial molar properties. Geochim Cosmochim Acta 51:2931-2946

Lange RA, Carmichael ISE (1990) Thermodynamic properties of silicate liquids with an emphasis on density, thermal expansion and compressibility. In: Nicholls J, Russell K (eds) Reviews in mineralogy, Mineralogical Society of America 24:25-64

Liu Q, Lange RA (2001) The partial molar volume and thermal expansivity of $\mathrm{TiO}_{2}$ in alkali silicate melts: systematic variation with Ti coordination. Geochim Cosmochim Acta 65:2379-2393

Ochs FA, Lange RA (1999) The density of hydrous magmatic liquids. Science 283:1314-1317

Pan V, Holloway JR, Hervig RL (1991) The pressure and temperature-dependence of carbon-dioxide solubility in tholeiitic basalt melts. Geochim Cosmochim Acta 55:1587-1595

Rigden SM, Ahrens TJ, Stolper EM (1989) High-pressure equation of state of molten anorthite and diopside. J Geophys Res 94:9508-9522

Rolin M, Recapet JM (1964) Contribution a l'étude des proprietes thermódynamiques des carbonates alcalins. III. Courbes d'enthalpies en fonction de la température et chaleurs de fusion de $\mathrm{Na}_{2} \mathrm{CO}_{3}, \mathrm{Li}_{2} \mathrm{CO}_{3}, \mathrm{~K}_{2} \mathrm{CO}_{3}$ et de leur mélange eutectique ternaire. B Soc Chim Fr 10:2504-2510

Schneider SJ, Levin EM (1973) Polymorphism of $\mathrm{K}_{2} \mathrm{CO}_{3}$. J Am Ceram Soc 56:218-219

Smyth JR, McCormick TC (1995) Crystallographic data for minerals. In: Ahren T (ed) Mineral physics and crystallography. AGU Ref Shelf 2, Washington, DC, pp 29-44

Spedding PL (1970) Densities and molar volumes of molten alkali carbonate binary mixtures J Electrochem Soc 117:177-183

Stein DJ, Stebbins JF, Carmichael ISE (1986) Density of molten sodium aluminosilicates. J Am Ceram Soc 69:396-399

Stixrude L, Bukowinski MST (1990) Fundamental thermodynamic relations and silicate melting with implications for the constitution of D". J Geophys Res 95:19311-19327

Stolper E, Holloway JR (1988) Experimental-determination of the solubility of carbon-dioxide in molten basalt at low-pressure. Earth Planet Sci Lett 87:397-408

Thibault Y, Holloway JR (1994) Solubility of $\mathrm{CO}_{2}$ in a Ca-rich leucitite - effects of pressure, temperature, and oxygen fugacity. Contrib Mineral Petrol 116:216-224

Treiman AH, Schedl A (1983) Properties of carbonatite magma and processes in carbonatite magma chambers. J Geol 91:437447

Tuinstra $\mathrm{F}$ (1986) The thermal expansion of $\mathrm{Na}_{2} \mathrm{CO}_{3}$. Z Kristallogr 177:155-164

Vorob'ev GV, Pal'guev SF, Karpache SV (1961) Density and electrical conductivity of the fused alkali metal carbonates. II. Systems $\mathrm{Na}_{2} \mathrm{CO}_{3}-\mathrm{Li}_{2} \mathrm{CO}_{3}$ and $\mathrm{K}_{2} \mathrm{CO}_{3}-\mathrm{Li}_{2} \mathrm{CO}_{3}$. Trans Inst Elektrokhim 2:115-120

Ward AT, Janz GJ (1965) Molten carbonate electrolytes: electrical conductance, density and surface tension of binary and ternary mixtures. Electrochim Acta 10:849-857

Wolff JA (1994) Physical properties of carbonatite magmas inferred from molten salt data, and application to extraction patterns from carbonate-silicate magma chambers. Geol Mag 131:145153

Zhu H, Saito T, Sato Y, Yamamura T, Shimakage K, Ejima T (1991) Ultrasonic velocity and absorption coefficient in molten alkali metal nitrates and carbonates. J Jpn Inst Metals 55:937944 